\title{
Creating Shared Value Through Implementing Vocational Rehabilitation In The Corporate Social Responsibility Strategy: A Literature Review
}

\author{
Boris MIETHLICH \\ Faculty of Management, Comenius University in Bratislava, Bratislava, Slovakia, \\ boris.miethlich@fm.uniba.sk \\ Ludomír ŠLAHOR \\ Faculty of Management, Comenius University in Bratislava, Bratislava, Slovakia, \\ ludomir.slahor@fm.uniba.sk
}

\begin{abstract}
After an accident or illness, it may be difficult or even impossible to return to work. Although occupational safety and health (OHS) are essential elements of corporate social responsibility (CSR), support for employees returning to work or vocational rehabilitation are rarely part of the CSR strategy. The aim of this paper is to assess and synthesize the current state of research of vocational rehabilitation in the context of CSR. A literature analysis was conducted to examine the need to address vocational rehabilitation as part of the CSR strategy as well as the existing approaches for implementation. Vocational rehabilitation is an important part of a company's social responsibility towards its employees as well as towards society. The promotion of vocational rehabilitation should be an essential element of the CSR strategy and can create shared value. However, a commitment to vocational rehabilitation alone is not enough; the commitment must be explicitly described and go beyond the legal minimum. That can be done, for example, through return-to-work (RTW) policies, proactive initiation and coordination of the rehabilitation process, the adaptation of the workplace and work activities, the institutionalization of sheltered workplaces, and a specialist unit for vocational rehabilitation within the company. Particularly access for external persons to the company's sheltered workplaces, internships or entry-level positions is a critical aspect for substantially promoting vocational rehabilitation and achieving additional shared value. Vocational rehabilitation as part of the CSR strategy must continue to be examined empirically, in particular "best practice" approaches from business practice.
\end{abstract}

Keywords: vocational rehabilitation, disability management, CSR, shared value

\section{Introduction}

It can happen to everyone. After an accident or a serious illness, it can be difficult or even impossible to return to work due to a long absence from work or permanent restraints. In this case, a vocational rehabilitation takes place after the health-related rehabilitation is completed. Vocational rehabilitation enables people with temporary, imminent or permanent disabilities to enter, return or remain in employment (BSRM, 2000; Waddell, Burton \& Kendall, 2008).

Various studies show that people who are employed recover almost twice as fast as people who are unemployed. Likewise, the longer a person stays away from the workplace, the less likely they are to return to their original workplace. The return to the company to a possibly adapted workplace during the healing process enables the person concerned to remain involved in the business and formally and informally in contact with the company, employees, and superiors. The maintained employment in the company offers the person concerned psychologically important security during recovery (Doucette, 2004).

In Europe, there is a large number of social security agencies that are responsible for the consequences of disability but also for carrying out vocational rehabilitation. What these insurance carriers have in common is that they pursue the fundamental principle of "rehabilitation before pension" (Waddell et al., 2008). In principle, a causal relationship is assumed between the severity of 
Vision 2020: Sustainable Economic Development and Application of Innovation Management

the health impairment or disability and the potential of earning capacity. Thus, all medical and vocational rehabilitation opportunities are exhausted in order to minimize or prevent a long-term or permanent inability to earn an income (Fournier-Buchs \& Gobelet, 2006). In vocational rehabilitation, the insurance carriers work with specialized institutions (e.g., sheltered workshops, work centers, social enterprises for work integration, employment support) and above all with companies (Fournier-Buchs \& Gobelet, 2006). The support of the insurance carriers is comprehensive for the affected persons themselves as well as for companies. The inclusion of companies in vocational rehabilitation is the most efficient and effective option (Morger, 2006). In contrast, the use of specialized institutions is comparatively lengthy and cost-intensive. However, often there is no suitable alternative position at the previous employer and the person concerned is dependent on being given a chance in another company.

The commitment and generous cooperation of companies with social security agencies are basic conditions for successful vocational rehabilitation (Seing, Stahl, Nordenfelt, Bülow \& Ekberg, 2012; Pilet, 2006). The company's commitment to vocational rehabilitation seems to require an appropriate corporate culture (Araten-Bergman, 2016; Bruyère, von Schrader, Coduti, \& Bjelland, 2010; Cullen, Silverstein \& Foley, 2008). For example, in addition to the commitment of management (AratenBergman, 2016; Higgins, O'Halloran \& Porter, 2012; Waddell \& Burton, 2005; Kenny, 1995), a climate of organizational diversity is an significant success factor for the integration of people with disabilities into the workforce (Araten-Bergman, 2016; Bengisu \& Balta, 2011).

Persons with disabilities or long-term health concerns and groups with other barriers to labor market entry or job retention belong to vulnerable groups (Van Berkel, Ingold, McGurk, Boselie \& Bredgaard, 2017). These vulnerable labor market groups represent a large and growing part of the population in many countries (Dean, 2013). It can be assumed that in each country 10 to 20 percent of the population are affected by disabilities (Collins, 2007). Invalidity benefits, as compensation for salary, are obtained on average by 6 percent of the working age population in OECD countries (De Jong, 2010).

Appropriate social responsibility assumed by companies is a social necessity (Marsden \& Andriof, 1998). Socially responsible corporate management also means maintaining an overall functioning of the economy, which is the basis for the continuation of the company's business activities (Elkington, 2007; Porter \& Kramer, 2006). The "Corporate Shared Value" approach explains how socially responsible and sustainable corporate management can contribute to the corporate success and realize competitive advantages. Corporate social responsibility (CSR) activities can generate shared value for companies and society, which in turn leads to increasing prosperity. Increasing prosperity of the society in which the company operates has in return a positive influence on the company itself (Porter \& Kramer, 2006).

In this article, CSR is understood as a voluntary commitment by companies that goes beyond the legal requirements with the aim of generating profits in an ecologically, economically and socially acceptable manner. As such, CSR is not an additional activity of a company, but a way of conducting core business (Bergius, 2005). In doing so, the central question is not how profits are distributed, but how they are generated (Leitschuh, 2008).

Although a growing interest in a comprehensive understanding of the implementation of CSR initiatives could be perceived in the past two decades (Wang, Tong, Takeuchi \& George, 2016), there is only little reference in the literature to the implementation and adaptation of vocational rehabilitation or related concepts (like disability management or RTW programs) as a part of the CSR strategy (Seing, MacEachen, Ekberg \& Stahl, 2015; Monachino \& Moreira, 2014; Hart 2010). That is surprising as various aspects of vocational rehabilitation have already been extensively empirically investigated (Waddell et al., 2008) and vocational rehabilitation itself is an essential social responsibility of every company towards its employees and society.

The aim of this article is to present the current situation of vocational rehabilitation as part of CSR strategies. The research is based on literature concerning vocational rehabilitation in companies in 
Vision 2020: Sustainable Economic Development and Application of Innovation Management

general and specifically in CSR. This article explains why vocational rehabilitation must be addressed as part of the CSR strategy and how the associated CSR activities can be adapted within the company.

\section{Methodology}

The research is based on a comprehensive search for published peer-reviewed literature. The research was conducted in a first step using the databases Web of Science, and SCOPUS, limited to the subject areas business, economics, and management. In a second step, the reference lists of all previously included articles were checked to find additional studies. The titles, abstracts, and keywords of papers were scanned to identify papers related to vocational rehabilitation, occupational rehabilitation, return-to-work, disability management, and employment of persons with disabilities in association with business, corporate shared value and corporate social responsibility. For in depth analysis, articles were selected that describe business management aspects of vocational rehabilitation in companies and/or the connection between vocational rehabilitation and CSR and that were published in English in peer-reviewed journals, conference proceedings or books.

\section{The Concept and Procedure of Vocational Rehabilitation}

The organization of vocational rehabilitation varies from country to country and in some cases from region to region. Nevertheless, vocational rehabilitation always pursues the same goal of maximizing the capability of the person to return to meaningful employment (BSRM, 2000) and to earn their full income again. It can be concluded, that vocational rehabilitation is ultimately about the rehabilitation of earning. The usual course of vocational rehabilitation, from acute care after an accident or illness to return to the labor market, is shown below:

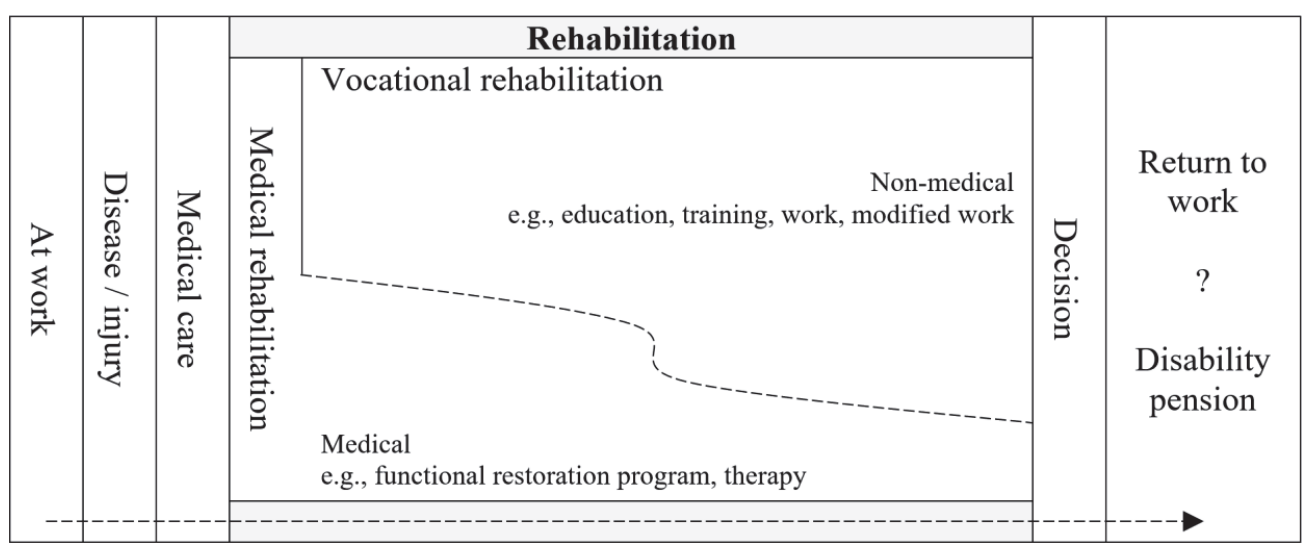

Figure: Process of vocational rehabilitation, own presentation according to Selander et al. (2002)

In the case of restraints that remain after medical treatment, the person concerned may undergo outpatient or inpatient medical rehabilitation. Subsequently, vocational rehabilitation can be initiated and conducted simultaneously with medical and non-medical interventions (Gobelet \& Franchignoni, 2006; Selander, Marnetoft, Bergroth \& Ekholm 2002). In order to achieve a positive effect, medical and vocational rehabilitation must be addressed and coordinated equitably (Waddell et al., 2008; Doucette, 2004). If the vocational rehabilitation measures fail and result in disability, the person receives a disability pension corresponding to the degree of disability (Fournier-Buchs \& Gobelet, 2006). The social security agencies themselves have a significant influence on the motivation of the people concerned to return to work. It is problematic when a pension seems more attractive than resuming work (Gobelet \& Franchignoni, 2006; Bell \& Smith, 2004). 
Vision 2020: Sustainable Economic Development and Application of Innovation Management

Vocational rehabilitation can be seen as an intervention or service (Waddell et al., 2008), which in theory and practice is limited to person-centered approaches (Barnes, 2003). Vocational rehabilitation, as a decisive intervention in the event of prolonged absence from work, can accelerate the return to work and thus minimize the number of working days lost, increase the productivity of limited employees, reduce early retirement and contain social costs in general (Doucette, 2004; Disler \& Pallant, 2001). In most countries, vocational rehabilitation is accompanied and coordinated by an RTW coordinator or case manager of the relevant social insurance carrier (Franche et al., 2005). Additionally, there are various measures financed by social security which can be used individually or in combination for vocational rehabilitation. For example, vocational assessment (job assessment and analysis), vocational and career guidance, retraining, further qualifications, workplace-related guidance and counseling, ergonomic adjustments in the workplace, functional rehabilitation programs and psychosocial interventions, and other support for enabling the return to work (Marnetoft, Selander, Bergroth \& Ekholm, 2001). Work is not always understood as part of rehabilitation, so vocational rehabilitation often includes educating everyone involved about the value of work for health and recovery (Waddell et al., 2008). These vocational rehabilitation interventions are almost identically applied to people with congenital or development-related disabilities who enter the labor market for the first time (Gobelet \& Franchignoni, 2006), return to work after a long absence or job change. Therefore, knowledge of vocational rehabilitation is also relevant to the employment of people with disabilities (Seino, Nomoto, Takezawa \& Boeltzig-Brown, 2017).

The terms "RTW", "disability management", and "workplace case management", are often used synonymously. The concepts all aim at reducing or preventing the inability to work as a result of accidents and illness through preventive measures within the company. Beyond that disability management is understood as part of the organization and corporate strategy (Geisen, Lichtenauer, Roulin \& Schielke, 2008). In addition to responsibility for safety systems and accident prevention, it also covers aspects of vocational rehabilitation. In this way, employees are supported and accompanied on their return to work after an accident or illness. Disability management often takes on an interface function between companies and social security, which is equivalent to occupational case management. Case management itself represents the methodological basis for the implementation of disability and RTW management and is generally used in medical and vocational rehabilitation (Wendt, 2001; Harder \& Scott, 2005; Geisen et al., 2008). The handling of cases in case management follows a systematic process structured in a control cycle consisting of the following steps: Recording, assessment, planning of measures, implementation, monitoring of measures and evaluation (Neuffer, 2007; Geisen et al., 2008). Case management also includes making services accessible and coordinating them, always with the aim of rapid and resource-saving case processing. An in-house specialist unit (e.g., disability management or occupational case management) can support the vocational rehabilitation process and bridge internal and external stakeholders cooperation and collaboration. It enables better exploitation of opportunities within the company, even across departments (e.g., by relocation, an adaptation of activities or the work environment) and at the same time a better understanding of "work disability" throughout the entire organization. However, the costs of setting up a specialist in-house unit are hardly bearable for SMEs (Gensby, Labriola, Irvin, Amick \& Lund, 2014). In-house specialist units can be problematic in vocational rehabilitation, especially with regard to conflicts of interest and personality protection. The involvement of an external RTW coordinator or a contract with a third-party disability management company to manage the medical information and return-to-work plan can help to avoid conflicts of interest and guarantee the person concerned a neutral, secure and trustworthy service. The inclusion of medical information and the associated handling of data protection can have a significant influence on the effectiveness of vocational rehabilitation, so a trustful relationship between the person concerned and the RTW coordinator is crucial (Doucette, 2004).

However, external RTW coordinators hardly know the company and the existing possibilities when searching for potential solutions. They have to rely on the assessments of the contact persons of the companies, who usually has only limited experience with the topic "work disability" (Franche et al., 2005). Overall, large companies have more work and tasks to offer than SMEs, allowing employees with limited capacity to work temporarily with tasks that are less demanding (Baril, Berthelette \& Massicotte, 2003). In contrast, vocational rehabilitation in a SME with a flat hierarchy is easier to 
Vision 2020: Sustainable Economic Development and Application of Innovation Management

coordinate and facilitate due to more straightforward processes and the smaller number of people involved (Friesen, Yassi, \& Cooper, 2001). Successful vocational rehabilitation requires the cooperation of employees and superiors (Baril, Clarke, Friesen, Stock \& Cole, 2003; Tweed, 1994). The direct superior is a key factor for a successful realization of the vocational rehabilitation and bears the main responsibility in particular with regard to designing an appropriate working environment and maintaining a balance between achieving the operational goals and finding suitable activities for the person to be rehabilitated (Holmgren \& Ivanoff, 2007).

Vocational rehabilitation carried out by the previous employer promises the greatest success. Whether it is a return to the previous position or to another job within the same company seems insignificant (Morger, 2006). The early commencement of vocational rehabilitation measures also significantly increases the chances of a long-term resumption of work (Fournier-Buchs \& Gobelet, 2006; Pilet, 2006). Active participation of the person concerned improves the work and activity tolerance, which prevents deconditioning and chronification, and reduces pain and the effects of illness or disability (Gobelet \& Franchignoni, 2006). Empirically, there is clear evidence that the duration of the inability to work is significantly reduced through adjustments to the workplace and contact between the health service provider and employer. It can be assumed that interventions such as early involvement of the employer, ergonomic advice at the workplace and the presence of an RTW coordinator or case manager will also significantly reduce the costs associated with the duration of the inability to work (Gensby et al., 2014; Tompa et al., 2008; Franche et al., 2005). At the same time, the risk of job losses is minimized (Doucette, 2004; Allaire, Li \& La Valley, 2003).

The process of vocational rehabilitation is complicated and includes complex interactions (Lefever, Decuman, Perl, Braeckman \& Van de Velde, 2018; Shaw, Hong, Pransky \& Loisel, 2008). A critical success factor is good cooperation and ensuring communication between all parties involved. A clear understanding of the requirements of the previous work and the current abilities of the person concerned are essential (Lefever et al., 2018; Gensby et al., 2014, p.4, Shaw et al., 2008). Poor communication, a lack of trust or disappointment can cause vocational rehabilitation to fail despite the person's ability to meet the requirements of adapted or regular work (Shaw et al., 2008). Practical experience has shown that vocational rehabilitation is easier and faster for serious but visible disabilities, such as paralysis or amputation, rather than for less severe but less visible disabilities. This circumstance can probably be explained by the fact that visible disabilities guarantee direct recognition by society or the environment. In contrast, a person suffering from a psychosomatic or mental illness, for example, has nothing that they can show to their environment so that the disability can be directly recognized (Pilet, 2006). Therefore, people with less visible disabilities often have to explain themselves to their environment and hope for understanding.

This indicates why a specialist unit or RTW coordinator is needed to facilitate and monitor the entire process of vocational rehabilitation (Lefever et al., 2018). Even if different insurance carriers offer many possibilities and instruments to support vocational rehabilitation, success depends largely on the economic and social environment (Morger, 2006). Central to this is the goodwill and willingness of business and companies (Seing et al., 2012; Pilet, 2006). Nevertheless, vocational rehabilitation is always an interaction of different actors and must be understood as a network task (Holmgren \& Ivanoff, 2007; Morger, 2006).

\section{Advantages for Companies through Vocational Rehabilitation}

In very few countries there is a quota system for the employment of people with disabilities or an obligation to participate in vocational rehabilitation. Irrespective of this, companies are interested not only in preventing accidents but also in keeping their injured employees and promoting their return to work. Most accident insurance contracts for companies are based on a bonus-malus system and can be positively influenced by those measures (Morger, 2006). In contrast, disability due to illness or congenital disability is covered by state insurance carriers (disability insurance). The premiums are paid privately by each person. Therefore, there is no bonus-malus system that affects the company's behavior (Fournier-Buchs \& Gobelet, 2006). 
Vision 2020: Sustainable Economic Development and Application of Innovation Management

Although only a small proportion of people who are ill or have an accident need additional support when returning to work, vocational rehabilitation seems to be a good business case for all involved stakeholders from an economic point of view. The cost advantages of vocational rehabilitation are empirically better proven than it might be the case in many other health and social policy fields. It can be assumed that the cost benefits arising from vocational rehabilitation outweigh the costs of implementation and the follow-up costs incurred if no intervention would take place (Waddell et al., 2008). Studies also show that vocational rehabilitation reduces overall disability rates and health costs (Cullen et al., 2008). The available research results come mainly from economically strong nations and are overall inconsistent (Howard-Wilsher et al., 2016). Nevertheless, the results tend to point to a positive contribution to business success (Tompa et al., 2008), although the extent varies from industry to industry (Tompa et al., 2010). However, due to the wide variety of disabilities and intervention options, it is almost impossible to accurately determine cost-effectiveness or cost benefits (Howard-Wilsher et al., 2016). Accordingly, no international consensus has yet been reached on the methodology of vocational rehabilitation as well as its effectiveness and efficiency (Lefever et al., 2018).

Monetary incentives and social security allowances seem to offer only short-term benefits to companies (Graffam, Smith, Shinkfield \& Polzin, 2002; Dean, 1988). However, vocational rehabilitation can usually be carried out with the available or minimal additional resources of a company and is therefore cost-effective or cost-neutral (Waddell et al., 2008). It even results in cost advantages, as employees can return to the work process more quickly and are more productive. Overall, vocational rehabilitation offers companies more benefits than costs (Graffam et al., 2002; Dean, 1988). The advantages mentioned in the literature that companies derive from vocational rehabilitation can be divided into three categories: Increasing productivity, reducing personnel costs, and maintaining the return on human capital. All these advantages ultimately lead to higher profitability for the company. It can be assumed that the sooner an affected employee can return to work, the less the production process or work processes are disturbed. Productivity increases as a result. If an affected employee can be retained in the company, the fluctuation rate and therefore also the personnel costs, for example for recruiting, selecting, hiring and training a replacement employee, are reduced. Losing an employee due to illness or accident reduces the return on investment in formal and practical training. Vocational rehabilitation thus also enables a company to maintain its investments in "human capital" (Dean, 1988).

Companies can benefit from additional advantages arising from a commitment to vocational rehabilitation. For example, people with disabilities represent a largely untapped market for products and services worldwide (Collins, 2007) as well as an enormous untapped labor potential (Buys et al., 2015; Collins, 2007). Through vocational rehabilitation, a company can develop an understanding of the needs and concerns of employees and customers with disabilities (Seino et al. 2017). In order to be prepared for the consequences and challenges of demographic change, an aging workforce and thus more chronic illnesses, as well as an increasing shortage of skilled workers, occupational safety and health (OHS) and vocational rehabilitation should be an integral part of every company's human resource management (Niehaus \& Marfels, 2010).

Positive social response to disability in the workplace reduces the stigma and threat of job loss (Cullen et al., 2008; Doucette, 2004; Millington et al., 2003). Employees who experience how the company takes care of sick or injured colleagues seem to have better resilience. Studies also indicate that the existence of a disability management or vocational rehabilitation program in a company is associated with fewer work-related burnout cases and an improved corporate culture (Cullen et al., 2008) as well as a positive influence on the job satisfaction of the persons concerned and their colleagues (Wagner et al. 2017; Millington et al., 2003). Additionally, several studies in Europe show that working conditions and job security have a significant and increasing influence on the incidence of illness and consequently on long-term and permanent disabilities (Pilet, 2006). The efforts of vocational rehabilitation have the potential to reduce absence due to illness, show a preventive effect, and improve the working atmosphere in general (Cullen et al., 2008). 
Vision 2020: Sustainable Economic Development and Application of Innovation Management

\section{Problems of Integrating Vocational Rehabilitation in Companies}

The political goal in various countries is to reduce the number of recipients of disability pensions, which is primarily to be achieved by increasing the eligibility criteria. Therefore, vocational rehabilitation is becoming even more strategically important for social security agencies and politics and the need for opportunities for vocational rehabilitation is becoming even greater (Buys et al., 2015).

However, even in countries with comprehensive legal obligations for companies, the process of vocational rehabilitation is often hampered by general problems. Employers barely fulfilled the legal obligations in the rehabilitation process. (Selander, 2016; Wiggett-Barnard \& Swartz, 2012; Clayton et al., 2011; Vilchinsky \& Findler, 2004; Selander, Marnetoft, Bergroth \& Ekholm, 1998). The cooperation of employers and social security insurances with other stakeholders is often not effective enough (Selander, 2016; Kärrholm, Ekholm, Ekholm, Bergroth, and Ekholm, 2008). The social security insurances see companies as their customers and shape their business relationships accordingly (Haines et al., 2018), which explains at least partly why companies do not have to fear any disadvantages or sanctions if they do not cooperate. Various studies show that non-compliance with vocational rehabilitation legislation often stems from companies expecting information and medical diagnosis from health care providers and insurance systems before vocational rehabilitation is initiated (Waddell \& Burton, 2005; Kenny, 1995).

Further reasons why companies are not involved in vocational rehabilitation and fail to comply with legal requirements can be attributed to poor communication and unclear responsibility among the stakeholders involved (Selander, 2016), a lack of commitment by the top management, a lack of alternative employment opportunities within the company, economic pressure or even employee displeasure and resistance of co-workers and superiors. Often the thinking that an employee must be completely healthy before returning to work also prevents vocational rehabilitation.

In vocational rehabilitation, companies are always caught between assuming social responsibility and meeting their operational targets (Seing et al., 2015; Seing et al., 2012; Holmgren \& Ivanoff, 2007). It also seems that companies are more concerned with their employees with high socio-economic status. Social responsibility towards the workforce is selective and often seems to depend on the current value of an employee in the workplace. In contrast, employees with a low socio-economic status are more likely to be reoriented outside the company - if they are supported at all (Seing et al., 2015). Extensive job adjustments are rare (Wahlin, Ekberg, Persson, Bernfort \& Öberg, 2012) and seem to deter employers (Seing et al., 2015). The majority of companies do not take over any responsibility for the vocational rehabilitation of their employees. Financial considerations seem to take precedence over legal and ethical considerations (Selander 2016; Seing et al., 2015; Holmgren \& Ivanoff, 2007). In addition, social security agencies often have too few human resources, who are therefore overworked and cannot sufficiently fulfill their task of coordinating and monitoring vocational rehabilitation. Nevertheless, companies are also of central importance in welfare states in order to achieve effective vocational rehabilitation (Selander, 2016).

\section{The Importance of Addressing Vocational Rehabilitation as Part of the CSR- Strategy}

There is a social and entrepreneurial necessity to promote and proactively approach vocational rehabilitation through companies themselves. The implementation of vocational rehabilitation in the CSR strategy offers important advantages and increases the chances of successful implementation in the company.

Vocational rehabilitation can be understood as an element of OHS (Koskela, 2014; AmponsahTawiah \& Dartey-Baah, 2012) or disability management (Tompa et al., 2008). Although OHS and vocational rehabilitation have a strategic economic value, it is above all a moral, ethical and social issue that companies must address as part of their CSR strategy (Cagno, Micheli, Masi, \& Jacinto, 2013). Vocational rehabilitation is an essential part of social commitment and thus of sustainable management (Monachino \& Moreira, 2014; Amponsah-Tawiah \& Dartey-Baah, 2012; Markel \& 
Vision 2020: Sustainable Economic Development and Application of Innovation Management

Barclay, 2009). It is an essential part of a company's care for its employees and thus a central concern of CSR (Cierniak-Emerych \& Zieba, 2014; Dura, 2014; Amponsah-Tawiah \& Dartey-Baah, 2012; Kornfeldova \& Myskova, 2012). It is not surprising that OHS is a subject in all international CSR management tools and instruments (Montero, Araque \& Rey, 2009). CSR plays an important role in promoting OHS. In most cases, CSR activities are far superior to the minimum requirements of worker protection in national and international legislation (Dura, 2014). Already in 1983, vocational rehabilitation was ratified by ILO Convention No. 159 of many states, which committed themselves to regularly revise the legislation and to create access to suitable measures for persons in need of support and to promote cooperation and coordination between state and private sector organizations with regard to vocational rehabilitation (ILO, 1983). Current strategies to promote OHS by the European Commission (EC) and the European Agency for Safety and Health at Work (EASHW) directly target companies and try to create a link between OHS and CSR to achieve strategic importance for companies through a business case (Zwetsloot et al., 2004). OHS and workplace innovation are also important goals of the EU 2020 Strategy on smart, sustainable and inclusive growth (EC, 2010).

The results of recent studies suggest that there is a link between new types of labor arrangements (e.g., freelancers, workers without an employment contract) and poor health, which consequently leads to an increased risk of work disability due to inadequate vocational rehabilitation (Vermeulen, Tamminga, Schellart, Ybema \& Anema, 2009). Due to the growing labour market flexibility and the flexibilization of the work, the importance of vocational rehabilitation will continue to increase for society and governments as well.

Since social security systems adapt little or insufficiently to economic developments (Vermeulen et al., 2009; Pilet, 2006), the social responsibility of companies are essential to create quickly more jobs for people with disabilities in order to integrate them into society (Csillag \& Gyori, 2016). In contrast to some European countries, in most countries there is no obligation for companies to engage in vocational rehabilitation, to professionally rehabilitate sick or injured employees (Morger, 2006) or to continue to employ them. This is an exclusively voluntary social commitment of a company. Overall, vocational rehabilitation and the employment of people with disabilities are important social concerns that companies must address as part of their CSR strategy (Miethlich \& Slahor, 2018; Kuznetsova, 2012). For companies, disability is a sensitive element of their CSR strategy and is addressed very differently. The challenge is not only to make the attitude towards the integration and inclusion of people with disabilities visible, but rather to adapt these CSR activities within the company itself. Especially with regard to the promotion of an appropriate corporate culture and working environment (Fasciglione, 2015; Kuznetsova, 2012). The promotion of vocational rehabilitation offers added value for a company's social responsibility. It shows the commitment towards society and the company is regarded as a good "corporate citizen". Additionally, it is good public relations work and makes disability-friendly values explicit in the workplace (Millington et al., 2003).

The adaptation of CSR and corporate guidelines regarding the employment of people with disabilities as well as vocational rehabilitation can be observed on a large scale mainly in large corporations and multinational companies. This phenomenon seems to be explained by the fact that these companies have better conditions and more resources to achieve diversity among employees and to address this concern (McMahon et al., 2008; Kuznetsova, 2012). The business sector (McMahon et al., 2008) and enterprise size have a significant impact on their employment policies, practices and labor needs (Bruyère et al., 2006). SMEs typically have few financial and human resources and the economic value of OHS is the primary driver. Nevertheless, even in SMEs, CSR should not be ignored as a driver in terms of improving working conditions and promoting vocational rehabilitation (Cagno et al., 2013).

Employment of people with disabilities extends corporate social responsibility (Samant et al., 2009) and is a real opportunity to take CSR seriously inside and outside the organization (Csillag \& Gyori, 2016). Awareness of CSR activities among customers and other stakeholders is a prerequisite for achieving benefits (Peloza \& Shang, 2011; Sen, Bhattacharya \& Korschun, 2006). Additional competitive advantages can be generated in connection with a positive reputation as a socially responsible company (Peloza \& Shang, 2011). Companies often functionalize CSR exclusively for 
Vision 2020: Sustainable Economic Development and Application of Innovation Management

their corporate image (Niehaus, 1997). However, a positive attitude and a generally positive perception of a company are not necessarily associated with increased intentions to retain or hire people with disabilities (Araten-Bergman, 2016). This is also reflected in the fact that the majority of multinational companies commit in their organizational norms and values to the employment of people with disabilities, but do not further include this in their corporate culture, human resources policies or working environment (Kuznetsova, 2012). But also many companies are engaged in vocational rehabilitation independently of a CSR strategy and thus miss the effective opportunity to gain a competitive advantage through CSR (Cierniak-Emerych \& Zieba, 2014).

Nevertheless, there is a lack of actual "disability champions", companies that can serve as models for other companies in terms of business cases and best practices (Fasciglione, 2015; Hernandez, McDonald, Divilbiss, Horin, Velcoff \& Donoso, 2008). Positive examples are important to demonstrate and understand the benefits of such activities (Markel \& Barclay, 2009; Hernandez et al., 2008). Further support could be provided by calling for CSR reporting, developing international CSR standards or awarding prizes to particularly committed companies (Csillag \& Gyori, 2016).

\section{Implementation of Vocational Rehabilitation as Part of the CSR Strategy}

Vocational rehabilitation should be described in concrete terms in the CSR strategy; a commitment alone is not sufficient (Miethlich \& Slahor, 2018; Fasciglione, 2015; Kuznetsova, 2012). The procedure and the course of vocational rehabilitation in the company should be recorded in RTW policies or a separate guideline or process (Gensby et al., 2014). However, even a guideline does not yet guarantee that vocational rehabilitation will be implemented in the company (Higgins et al., 2012). The combination of internal company guidelines or RTW policies and their implementation in the CSR strategy ensures that all executives involved speak the same management language and give vocational rehabilitation the same high priority (Montero et al., 2009). Other important factors for a successful implementation are: a common understanding of all stakeholders involved and a common intention with regard to interventions, goals, culture and practice concerning vocational rehabilitation (Higgins et al., 2012) as well as the awareness and knowledge of the employees on the program, processes and responsibilities (Doucette, 2004).

The commitment must go beyond any existing legal requirements. It can be achived with various additional measures that can be implemented individually or in combination as part of the CSR activity. For example, public and corporate awareness of vocational rehabilitation remains low (Niehaus \& Marfels, 2010). Companies can make their own commitment visible to the outside world through public relations work, highlighting the positive aspects of vocational rehabilitation and raising awareness of the topic (Fasciglione, 2015; Markel \& Barclay, 2009; Hernandez et al., 2008).

In vocational rehabilitation, the provision of work that the person concerned can perform with his or her current skills is central. This often requires ergonomic adjustments at the workplace or at the task itself (Gensby et al., 2014; Doucette, 2004). In addition, permanent sheltered workplaces, with work activities that make few demands and do not involve pressure to perform, can be firmly established in the company for the implementation of vocational rehabilitation, especially for the early phases. (Gensby et al., 2014; Higgins et al., 2012; Doucette, 2004). This can additionally accelerate the start of work for a person who is ill or had an accident. The company's internal opportunities for vocational rehabilitation or their sheltered workplaces could then also be made available to external persons to a certain, if not staffed by the company's own employees. In addition, persons in the process of vocational rehabilitation can be considered for internships or entry-level positions (Sherbin \& Kennedy, 2017).

Cooperation with external stakeholders, such as institutions for the disabled, municipal partners or social security agencies, is very advantageous. Practical examples show that this is a very effective CSR activity and can generate additional business opportunities (e.g., reputation as a socially responsible company, win-win-win situations, recruitment possibilities) (Thomsen \& Lauring, 2008). Through strategic cooperation with partners, companies can also benefit, as they receive support in recruiting, job matching, hiring and retaining qualified people with disabilities as well as carrying out vocational rehabilitation (Haines et al., 2018; Fraser, 2008). In addition, such cooperation can be 
Vision 2020: Sustainable Economic Development and Application of Innovation Management

helpful in supporting an affected employee in a necessary of external placement (Hayes, Randall \& Buys, 2013). Similarly, companies can also take particular account of people who need to reorient themselves for health reasons when filling internships or entry-level positions. Both can also be understood as an innovative approach to attracting and retaining the necessary specialists.

The promotion of vocational rehabilitation is most effective when CSR is anchored in the corporate culture. The commitment and support of all levels of the company, especially top management, is central and should be demonstrated regularly (Bruyère et al., 2010; Waddell \& Burton, 2005; Kenny, 1995).

Vocational rehabilitation can be institutionalized within the company itself by means of an internal specialist unit or contact person. The creation of such an interface improves the cooperation of the stakeholders involved (Gensby et al., 2014). Proactive initiation and coordination, with the information and involvement of key stakeholders, can lead significantly to the promotion of vocational rehabilitation due to early intervention (Gensby et al., 2014; Higgins et al., 2012; Doucette, 2004). Waiting for the initiation and coordination of vocational rehabilitation by social security or healthcare providers often takes an unnecessarily long time (Baril et. al, 2003b; Kenny, 1995), due to case numbers or work overload (Haines et al., 2018).

\section{Conclusion}

Occupational safety and health (OHS) is an important and central element of CSR and is taken into account in all CSR tools and instruments. However, if an employee falls ill or has an accident and then needs support when returning to work (e.g. in form of vocational rehabilitation), this is rarely part of the CSR strategy in practice. Also, in CSR literature, vocational rehabilitation received little attention so far.

In every company, vocational rehabilitation is an important element of social responsibility towards employees and thus towards society. Although social insurance offers many opportunities to support those affected in their vocational rehabilitation, they ultimately cannot be successful without the goodwill and commitment of companies. Vocational rehabilitation can therefore only really be promoted by the companies themselves.

Companies have the possibility to create a win-win-win situation through engaging in vocational rehabilitation, which can lead to a real "shared value". Vocational rehabilitation can prevent a person who is ill or had an accident from leaving work for a long time or permanently and it can enable a quick and goal-oriented return to work. For society this can reduce long-term social and health costs and keep tax revenues at least stable. Companies can assume an important social responsibility in an almost cost-neutral manner and at the same time maintain their own investments in human capital, reduce the duration of employees' inability to work and thus increase productivity. A company committed to vocational rehabilitation can benefit from the advantages that result from its reputation as a good "corporate citizen" or socially responsible company.

A company's commitment to vocational rehabilitation can also be an indicator of a socially responsible and caring employer. This has a certain signal effect on the workforce and can promote psychological vocational safety and thus strengthen the resilience of employees and reduce stressrelated illnesses.

Companies must address vocational rehabilitation as part of their CSR strategy. A pure commitment is not enough; companies must explicitly formulate in their CSR strategy how and in what form this concern is addressed. This is the only way to successfully implement a corresponding CSR initiative and ensure that everyone in the company speaks the same management language and attaches the same importance to this issue.

The implementation of vocational rehabilitation as a CSR initiative must go beyond the legal obligations and can take place, for example, by means of RTW policies, proactive initiation and coordination of the rehabilitation process, the adaptation of the workplace and work activities, the 
Vision 2020: Sustainable Economic Development and Application of Innovation Management

institutionalization of sheltered workplaces and a specialist center for vocational rehabilitation within the company. In particular, access for external persons to the company's sheltered workplaces, internships and entry positions is an increasingly important aspect, as new forms of work (e.g. freelancing) increasingly lead to "work disability" due to a lack of access to adequate vocational rehabilitation. Offering the company's internal vocational rehabilitation capacities to external persons can make a significant positive contribution to social development. The promotion of vocational rehabilitation by companies is, therefore, a valuable CSR activity that can generate additional shared value.

Given the few studies on this topic, it seems necessary to further empirically examine the implementation of vocational rehabilitation as part of the CSR strategy, as well as the resulting advantages, in the practice of companies and specifically evaluate best practice approaches. This can then serve on the one hand to quickly and purposefully adapt vocational rehabilitation as part of the company's CSR strategy and on the other hand to help social insurances and national and international regulators to develop measures and instruments further to support companies in promoting vocational rehabilitation.

\section{References}

Allaire, S. H., Li, W. and LaValley, M. P. (2003), 'Reduction of job loss in persons with rheumatic diseases receiving vocational rehabilitation: a randomized controlled trial,' Arthritis \& Rheumatism, 48(11), 3212-3218.

Amponsah-Tawiah, K. and Dartey-Baah, K. (2012), 'CSR-OHS: expert views, analysis and commentary on the two potent contrivances towards achieving MDGs,' Journal of Global Responsibility, 3(2), 224-234.

Araten-Bergman, T. (2016), 'Managers' hiring intentions and the actual hiring of qualified workers with disabilities,' The International Journal of Human Resource Management, 27(14), 1510-1530.

Baril, R., Berthelette, D. and Massicotte, P. (2003), 'Early return to work of injured workers: multidimensional patterns of individual and organizational factors,' Safety Science, 41(4), 277-300.

Baril, R., Clarke, J., Friesen, M., Stock, S. and Cole, D. (2003b), 'Management of return-to-work programs for workers with musculoskeletal disorders: a qualitative study in three Canadian provinces,' Social science \& medicine, 57(11), 2101-2114.

Barnes, C. (2003), 'Rehabilitation for disabled people: a 'sick'joke?,' Scandinavian Journal of Disability Research, 5(1), 7-23.

Bell, B. and Smith, J. (2004), 'Health, disability insurance and labour force participation,' Bank of England Working Papers, 218, 1-30.

Bengisu, M. and Balta, S. (2011), 'Employment of the workforce with disabilities in the hospitality industry,' Journal of Sustainable Tourism, 19(1), 35-57.

Bergius, S. (2005), 'Nachhaltiges wirtschaften schont die ressourcen und sichert das geschäft,' Handelsblatt. [Online], [Retrieved May 2018], https://www.handelsblatt.com/unternehmen/industrie/nachhaltiges-wirtschaften-schont-dieressourcen-und-sichert-das-geschaeft-wer-verantwortung-zeigt-muss-auch-verzichten/2513074.html

Bruyère, S. M., von Schrader, S., Coduti, W. and Bjelland, M. (2010), 'United states employment disability discrimination charges: implications for disability management practice,' International Journal of Disability Management, 5(2), 48-58. 
Vision 2020: Sustainable Economic Development and Application of Innovation Management

BSRM (2000), Vocational rehabilitation: the way forward, British Society of Rehabilitation Medicine, London.

Buys, N., Matthews, L. R. and Randall, C. (2015), 'Contemporary vocational rehabilitation in Australia,' Disability and rehabilitation, 37(9), 820-824.

Cagno, E., Micheli, G. J., Masi, D. and Jacinto, C. (2013), 'Economic evaluation of OSH and its way to SMEs: a constructive review,' Safety science, 53, 134-152.

Cierniak-Emerych, A. and Zięba, K. (2014), 'Working conditions as one of the areas for implementing the concept of corporate social responsibility,' Management, 18(1), 21-33.

Clayton, S., Barr, B., Nylen, L., Burström, B., Thielen, K., Diderichsen, F., Dahl, E. and Whitehead, M. (2011), 'Effectiveness of return-to-work interventions for disabled people: a systematic review of government initiatives focused on changing the behaviour of employers,' The European Journal of Public Health, 22(3), 434-439.

Collins, A. B. (2007), Opportunities and obligations in dealing with the disabled staff and customers in hospitality industry, Tourism Management in the 21st Century, Chang, P. R. (ed), Nova Science Publishers, New York.

Cullen, J. C., Silverstein, B. A. and Foley, M. P. (2008), 'Linking biomechanical workload and organizational practices to burnout and satisfaction,' Journal of Business and Psychology, 23(1-2), 63-71.

Csillag, S. and Gyori, Z. (2016), “Is there a place for me?" - employment of people with disabilities as part of CSR strategy,' Proceedings of the Strategica Conference: Opportunities and Risks in the Contemporary Business Environment, ISBN: 978-606-749-181-4, 20-22 October 2016, Bucharest, Romania, 860-872.

Dean, A. (2013), 'Tackling long-term unemployment amongst vulnerable groups,' OECD Local Economic and Employment Development (LEED) Working Papers, No. 2013/11.

Dean, D. (1988), 'Costs and benefits of vocational rehabilitation: an employer's perspective,' Employment Relations Today, 15(2), 141-147.

De Jong, P. R. (2011), 'Sickness, disability and work: breaking the barriers - a synthesis of findings across OECD countries,' Internationale Revue für Soziale Sicherheit, 64(3), 115-117.

Disler, P. B. and Pallant, J. F. (2001), 'Vocational rehabilitation - everybody gains if injured workers are helped back into work,' BMJ, 323(7305), 121-123.

Doucette, N. (2004), 'Modified work program: why bother?,' Proceedings of the SPE International Conference on Health, Safety, and Environment in Oil and Gas Exploration and Production, 29-31 March 2004, Calgary, Canada.

Dura, C. (2014), 'Occupational health and safety integration in corporate social responsibility policies within BRD-GSG Romania,' Annals of the University of Petroşani, Economics, 14(2), 59-70.

EC (2010), Europe 2020 - a european strategy for smart, sustainable and inclusive growth, European Commission, Brussels.

Elkington, J. (2007), Corporate sustainability, A to z of corporate social responsibility - a complete reference guide to concepts, codes and organisations, Visser, W. et al. (eds), John Wiley, Chichester. 
Vision 2020: Sustainable Economic Development and Application of Innovation Management

Fasciglione, M. (2015), Corporate social responsibility and the right to employment of persons with disabilities, Protecting the rights of people with autism in the fields of education and employment, Della Fina, V. and Cera, R. (eds), Springer, Cham.

Fournier-Buchs, M. F. and Gobelet, C. (2006), Vocational rehabilitation: the swiss model, Vocational rehabilitation, Gobelet, C. and Franchignoni, F. (eds), Springer, Paris.

Franche, R. L., Cullen, K., Clarke, J., Irvin, E., Sinclair, S. and Frank, J. (2005), 'Workplace-based return-to-work interventions: a systematic review of the quantitative literature.' Journal of Occupational Rehabilitation, 15(4), 607-630.

Fraser, R. T. (2008), 'Successfully engaging the business community in the vocational rehabilitation placement process,' Journal of Vocational Rehabilitation, 28(2), 115-120.

Friesen, M. N., Yassi, A. and Cooper, J. (2001), 'Return-to-work: the importance of human interactions and organizational structures,' Work, 17(1), 11-22.

Geisen, T., Lichtenauer, A., Roulin, C. and Schielke, G. (2008), Disability management im unternehmen: untersuchungen in einzelnen unternehmen in der schweiz, Beiträge zur sozialen sicherheit, BSV, Olten.

Gensby, U., Labriola, M., Irvin, E., Amick, B. C. and Lund, T. (2014), 'A classification of components of workplace disability management programs: results from a systematic review,' Journal of occupational rehabilitation, 24(2), 220-241.

Gobelet, C. and Franchignoni, F. (2006), Vocational rehabilitation, Vocational rehabilitation, Gobelet, C. and Franchignoni, F. (eds), Springer, Paris.

Graffam, J., Smith, K., Shinkfield, A. and Polzin, U. (2002), 'Employer benefits and costs of employing a person with a disability,' Journal of Vocational Rehabilitation, 17(4), 251-263.

Haines, K., Soldner, J. L., Zhang, L., Saint Laurent, M. L., Knabe, B., West-Evans, K., Mock, L. and Foley, S. (2018), 'Vocational rehabilitation and business relations: Preliminary indicators of state VR agency capacity,' Journal of Vocational Rehabilitation, 48(1), 133-145.

Hayes, C. A., Randall, C. and Buys, N. (2013), 'The resume-development process and its impact on job-search behaviour,' International Journal of Disability Management, 8, E2.

Harder, H. and Scott, L. R. (2005), Comprehensive Disability Management. Elsevier Churchill Livingston.

Hart, S. M. (2010), 'Self-regulation, corporate social responsibility, and the business case: do they work in achieving workplace equality and safety?,' Journal of Business Ethics, 92(4), 585-600.

Hernandez, B., McDonald, K., Divilbiss, M., Horin, E., Velcoff, J. and Donoso, O. (2008), 'Reflections from employers on the disabled workforce: focus groups with healthcare, hospitality and retail administrators,' Employee Responsibilities and Rights Journal, 20(3), 157-164.

Higgins, A., O'Halloran, P. and Porter, S. (2012), 'Management of long term sickness absence: a systematic realist review,' Journal of occupational rehabilitation, 22(3), 322-332.

Holmgren, K. and Ivanoff, S. D. (2007), 'Supervisors' views on employer responsibility in the return to work process. A focus group study,' Journal of occupational rehabilitation, 17(1), 93-106. 
Vision 2020: Sustainable Economic Development and Application of Innovation Management

Howard-Wilsher, S., Irvine, L., Fan, H., Shakespeare, T., Suhrcke, M., Horton, S., Poland, F., Hooper, L. and Song, F. (2016), 'Systematic overview of economic evaluations of health-related rehabilitation,' Disability and health journal, 9(1), 11-25.

ILO (1983), 'C159 - Vocational Rehabilitation and Employment (Disabled Persons) Convention No. 159,' International Labour Organization. [Online], [Retrieved May 01, 2018], http://www.ilo.org/dyn/normlex/en/f?p=NORMLEXPUB:12100:0::NO::P12100_INSTRUMENT_ID :312304

Kärrholm, J., Ekholm, K., Ekholm, J., Bergroth, A. and Ekholm, K. S. (2008), 'Systematic cooperation between employer, occupational health service and social insurance office: a 6-year followup of vocational rehabilitation for people on sick-leave, including economic benefits,' Journal of Rehabilitation Medicine, 40(8), 628-636.

Kenny, D. (1995), 'Barriers to occupational rehabilitation: an exploratory study of long term injured workers,' Journal of Occupational Health and Safety, Australia and New Zealand, 11(3), 249.

Kornfeldová, M. and Myšková, R. (2012), 'Health and safety at work-part of corporate social responsibility,' Scientific Papers of the University of Pardubice. Series D, Faculty of Economics \& Administration, 18(25), 90-99.

Koskela, M. (2014), 'Occupational health and safety in corporate social responsibility reports,' Safety Science, 68, 294-308.

Kuznetsova, Y. (2012), 'Inclusive corporate culture and employment of persons with disabilities: analysis of CSR strategies of multinational enterprises in norway and the UK,' Proceedings of the University Forum for Human Resource Development (UFHRD) Conference, 29 October - 5 November 2012, Famalicão Portugal.

Leitschuh, H. (2008), 'CSR ist gut, nachhaltig wirtschaften ist besser,' UmweltWirtschaftsForum $(U w f), 16(1), 45-48$.

Lefever, M., Decuman, S., Perl, F., Braeckman, L. and Van de Velde, D. (2018), 'The efficacy and efficiency of disability management in job-retention and job-reintegration. a systematic review,'Work, 59(4), 501-534.

McMahon, B. T., Rumrill, P. D., Roessler, R., Hurley, J. E., West, S. L., Chan, F. and Carlson, L. (2008), 'Hiring discrimination against people with disabilities under the ADA: Characteristics of employers,' Journal of Occupational Rehabilitation, 18(2), 112.

Markel, K. S. and Barclay, L. A. (2009), 'Addressing the underemployment of persons with disabilities: recommendations for expanding organizational social responsibility,' Employee Responsibilities and Rights Journal, 21, 305-318.

Marnetoft, S. U., Selander, J., Bergroth, A. and Ekholm, J. (2001), 'Factors associated with successful vocational rehabilitation in a swedish rural area,' Journal of Rehabilitation Medicine, 33(2), 71-78.

Marsden, C. and Andriof, J. (1998), 'Towards an understanding of corporate citizenship and how to influence it,' Citizenship Studies, 2(2), 329-352.

Miethlich, B. and Slahor, L. (2018), 'Employment of persons with disabilities as a corporate social responsibility initiative: necessity and variants of implementation,' Proceedings of the 6th CBU International Conference Proceedings: Innovations in Science and Education, 21-23 March 2018, Prague, Czech Republic. 
Vision 2020: Sustainable Economic Development and Application of Innovation Management

Millington, M. J., Miller, D. M., Asner-Self, K. K. and Linkowski, D. (2003), The business perspective on employers, disability and vocational rehabilitation, Work and disability, Szymanski, E. and Parker, R. (eds), Pro-Ed, Austin.

Monachino, M. S. and Moreira, P. (2014), 'Corporate social responsibility and the health promotion debate: an international review on the potential role of corporations,' International Journal of Healthcare Management, 7(1), 53-59.

Montero, M. J., Araque, R. A. and Rey, J. M. (2009), 'Occupational health and safety in the framework of corporate social responsibility,' Safety Science, 47(10), 1440-1445.

Morger, W. (2006), The point of view of the insurance company, Vocational rehabilitation, Gobelet, C. and Franchignoni, F. (eds), Springer, Paris.

Neuffer, M. (2007), Case management: soziale arbeit mit einzelnen und familien. Juventa Verlag, München.

Niehaus, M. (1997), Barrieren gegen die beschäftigung langfristig arbeitsloser behinderter, Behinderte auf dem arbeitsmarkt: wege aus dem abseits, Niehaus, M. and Montada, L. (eds), Campus Verlag, Frankfurt.

Niehaus, M. and Marfels, B. (2010), 'Competencies and tasks of disability management professionals in germany,' International Journal of Disability Management, 5(2), 67-72.

Peloza, J. and Shang, J. (2011), 'How can corporate social responsibility activities create value for stakeholders? a systematic review,' Journal of the academy of Marketing Science, 39(1), 117-135.

Pilet, F. (2006), Inability to work, disability and vocational rehabilitation: does the general practitioner have a role to play in these processes?, Vocational rehabilitation, Gobelet, C. and Franchignoni, F. (eds), Springer, Paris.

Porter, M. E. and Kramer, M. R. (2006), 'Strategy and society: the link between competitive advantage and corporate social responsibility,' Harvard Business Review, 84(12), 78-92.

Samant, D., Soffer, M., Hernandez, B., Adya, M., Akinpelu, O., Levy, J. M., Repoli, E., Kramer, M. and Blanck, P. (2009), 'Corporate culture and employment of people with disabilities: role of social workers and service provider organizations,' Journal of social work in disability \& rehabilitation, 8(3-4), 171-188.

Seing, I., MacEachen, E., Ekberg, K. and Ståhl, C. (2015), 'Return to work or job transition? employer dilemmas in taking social responsibility for return to work in local workplace practice,' Disability and rehabilitation, 37(19), 1760-1769.

Seing, I., Ståhl, C., Nordenfelt, L., Bülow, P. and Ekberg, K. (2012), 'Policy and practice of work ability: a negotiation of responsibility in organizing return to work,' Journal of occupational rehabilitation, 22(4), 553-564.

Seino, K., Nomoto, A., Takezawa, T. and Boeltzig-Brown, H. (2017), The diversity management for employment of the persons with disabilities: evidence of vocational rehabilitation in the united states and japan, Handbook of Research on Human Factors in Contemporary Workforce Development, Christiansen, B. and Chandan, H. C. (eds), Business Science Reference, Hershey.

Selander, J. (2016), 'Is employer-based disability management necessary in a social-democratic welfare state like sweden?,' International Journal of Disability Management, 11, E4. 
Vision 2020: Sustainable Economic Development and Application of Innovation Management

Selander, J., Marnetoft, S. U., Bergroth, A. and Ekholm, J. (1998), 'The process of vocational rehabilitation for employed and unemployed people on sick-leave: employed people vs unemployed people in stockholm compared with circumstances in rural jamtland, sweden,' Scandinavian journal of rehabilitation medicine, 30(1), 55-60.

Selander, J., Marnetoft, S. U., Bergroth, A. and Ekholm, J. (2002), 'Return to work following vocational rehabilitation for neck, back and shoulder problems: risk factors reviewed,' Disability and Rehabilitation, 24(14), 704-712.

Sen, S., Bhattacharya, C. B. and Korschun, D. (2006), 'The role of corporate social responsibility in strengthening multiple stakeholder relationships: a field experiment,'Journal of the Academy of Marketing science, 34(2), 158-166.

Shaw, W., Hong, Q. N., Pransky, G. and Loisel, P. (2008), 'A literature review describing the role of return-to-work coordinators in trial programs and interventions designed to prevent workplace disability,' Journal of Occupational Rehabilitation, 18(1), 2-15.

Sherbin, L. and Kennedy, J. T. (2017), 'The case for improving work for people with disabilities goes way beyond compliance,' Harvard Business Review. [Online], [Retrieved May 01, 2018], https://hbr.org/2017/12/the-case-for-improving-work-for-people-with-disabilities-goes-way-beyondcompliance

Tompa, E., De Oliveira, C., Dolinschi, R. and Irvin, E. (2008), 'A systematic review of disability management interventions with economic evaluations,'Journal of Occupational Rehabilitation, 18(1), 16-26.

Tompa, E., Dolinschi, R., De Oliveira, C., Amick, B. C. and Irvin, E. (2010), 'A systematic review of workplace ergonomic interventions with economic analyses,'Journal of Occupational Rehabilitation, 20(2), 220-234.

Tweed, V. (1994), 'Workers' comp strategies. simple answers to a complex problem,' Business and health, 12(10), 57-8.

Thomsen, C. and Lauring, J. (2008), 'Practicing the business of corporate social responsibility: a process perspective,' International Journal of Business Governance and Ethics, 4(2), 117-131.

Van Berkel, R., Ingold, J., McGurk, P., Boselie, P. and Bredgaard, T. (2017), 'Editorial introduction: An introduction to employer engagement in the field of HRM. Blending social policy and HRM research in promoting vulnerable groups' labour market participation,' Human Resource Management Journal, 27(4), 503-513.

Vermeulen, S. J., Tamminga, S. J., Schellart, A. J., Ybema, J. F. and Anema, J. R. (2009), 'Return-towork of sick-listed workers without an employment contract - what works?,' BMC Public Health, 9(1), 232.

Vilchinsky, N. (2004), 'Attitudes toward israel's equal rights for people with disabilities law: a multiperspective approach,' Rehabilitation Psychology, 49(4), 309-316.

Waddell, G. and Burton, A. K. (2005), 'Concepts of rehabilitation for the management of low back pain,' Best Practice \& Research Clinical Rheumatology, 19(4), 655-670.

Waddell, G., Burton, A. K. and Kendall, N. A. (2008). Vocational rehabilitation - what works, for whom and when? (report for the vocational rehabilitation task group), TSO, London. 
Vision 2020: Sustainable Economic Development and Application of Innovation Management

Wagner, S., Harder, H., Scott, L., Buys, N., Yu, I., Geisen, T., Randall, C., Lo, K., Tang, D., FraessPhillips, A., Hassler, B. and Howe, C. (2017), 'Canadian employee perspectives on disability management,' International Journal of Disability Management, 12, E3.

Wåhlin, C., Ekberg, K., Persson, J., Bernfort, L. and Öberg, B. (2012), 'Association between clinical and work-related interventions and return-to-work for patients with musculoskeletal or mental disorders,' Journal of rehabilitation medicine, 44(4), 355-362.

Wang, H., Tong, L., Takeuchi, R. and George, G. (2016), 'Corporate social responsibility: an overview and new research directions thematic issue on corporate social responsibility,' Academy of Management Journal, 59 (2), 534-544.

Wendt, W. R. (2001), Case Management im Sozial- und Gesundheitswesen. Lambertus, Freiburg im Breisgau.

Wiggett-Barnard, C. and Swartz, L. (2012), 'What facilitates the entry of persons with disabilities into South African companies?,' Disability and Rehabilitation, 34(12), 1016-1023.

Zwetsloot, G., Starren, A., Schenk, C., Heuverswyn, K., Kauppinnen, K., Lindstrom, K., Kuhn, K., Zwink, E., Lentisco, F., Vaselli, D., Pujol, L. Bestraten, M., Shearn, P., Kenny, L., Goudswaard, A. and van de Bovenkamp, M. (2004), Corporate social responsibility and safety and health at Work, European Agency for Safety and Health at Work, Office for Official Publications of the European Communities, Luxembourg. 